\title{
НИЗКОТЕМПЕРАТУРНАЯ ДЕСТРУКЦИЯ ГОРЮЧЕГО СЛАНЦА ЯРЕНГСКОГО МЕСТОРОЖДЕНИЯ КОМИ АССР
}

Lia NAPPA, I. KLESMENT, Natalja VINK. JARENGA (KOMI ANSV) POLEVKIVI MADALATEMPERATUURILINE DESTRUKTSIOON

Lia NAPPA, I. KLESMENT, Natalya VINK. THE LOW TEMPERATURE DESTRUCTION OF YARENGA (KOMI ASSR) OIL SHALE

Подробная характеристика изучаемой пробы, описание выделения и анализ битумоидов, а также смолы полукоксования приведены в [']. Для опытов использовали измельченный сланец из шурфа № 362 Яренгского участка. Его показатели: условное органическое вещество (ОВ) $37,5 \%$; элементный состав ОВ, \%: С 70,4; Н 7,9; N 1,5; S 5,5; O 14,7 (по разности). В яренгском сланце кислорода значительно меньше, чем в сланце другого месторождения Коми АССР - Сысольского [ㄹ. В автоклаве были проведены: 1) каталитическая гидрогенизация в среде бензола с первоначальным давлением водорода 3 МПа, катализатор молибдат аммония в расчете $1 \%$ Мо на ОВ; 2) термическое растворение в среде бензола; 3) конверсия $10 \%$-ным щелочным раствором. Все опыты проводили в качающемся автоклаве емкостью 400 мл при температуре $380^{\circ} \mathrm{C}$ в течение 3 ч. Соотношение сланец : растворитель (вода) 1:10 (20 и 200 г). Из таблицы видно, что при конверсии щелочным раствором получается самый низкий выход смолы: на 16\% ниже, чем при полукоксовании. В этом отношении яренгский сланец схож со сланцами Белорусского, Сысольского и Сузакского месторождений, но отличается от сланцев месторождений Боров Дол (Болгария), Чаганского и, особенно, от эстонских граптолитовых аргиллитов, выходы смолы из которых значительно выше при конверсии, чем при полукоксовании. Как известно, щелочь разрушает связь между ОВ и минеральной частью. Очевидно, на выход смолы оказывает влияние и природа минерального вещества. Термическое растворение повышает выход смолы из яренгского сланца примерно на $10 \%$, но он остается ниже выхода смолы полукоксования. Такое же явление имело место при деструкции сернистого сланца Чаганского месторождения [3]. Зато самый высокий выход смолы получался при каталитической гидрогенизации: в смолу перешло 55\% ОВ. Каталитическая гидрогенизация с подачей в автоклав газообразного водорода с первоначальным давлением от 3 до $5 \mathrm{MПа} \mathrm{дала} \mathrm{наиболее}$ высокий выход жидких продуктов для всех изученных горючих сланцев различных месторождений. В случае высокосернистых сланцев (чаганский, сысольский), где содержится относительно мното пирита, в процессах термической деструкции образующийся сероводород может действовать как катализатор гидрогенизации.

Смолы имеют более или менее одинаковый элементный состав, нет большого различия и в групповом составе. Смола автоклавной обработки менее ароматическая и содержит почти в три раза меньше серы по сравнению со смолой полукоксования. В случае сланца Чаганского месторождения такое резкое снижение серы наблюдалось лишь при каталитической гидрогенизации, а при конверсии оно снизилось лишь на $30 \%$. Образующийся газ содержит много двуокиси углерода и метана, 
Выходы и характеристика продуктов термической деструкции яренгского сланца

\begin{tabular}{|c|c|c|c|c|}
\hline Показатель & $\begin{array}{c}\text { Полукоксо- } \\
\text { вание ['] }\end{array}$ & \begin{tabular}{|c|} 
Каталити- \\
ческая гид- \\
рогенизация \\
$1 \%$ Мо на \\
ОВ. \\
Начальное \\
давление \\
$\mathrm{H}_{2}-3 \mathrm{MПа}$
\end{tabular} & $\begin{array}{l}\text { Tермическое } \\
\text { растворение } \\
\text { в бензоле }\end{array}$ & $\begin{array}{c}\text { Конверсия } \\
10 \% \text {-ным } \\
\text { раствором } \\
\text { NaOH }\end{array}$ \\
\hline
\end{tabular}

Выходы, вес. \% на ОВ

смола
твердый остаток
пирогенная вода

газ и потери

Характеристика смол:

элементный состав, вес. \%

углерод

водород

азот

сера

кнслород

групповой состав, вес. \%:

неароматические углеводороды

моноароматические углеводороды

конденсированные ароматические углеводороды

нейтральные кислородные соединения

в том числе фенолы
37

35

8
20
55

12

33
29

30

$\overline{41}$

21

13

$\overline{66}$

а также значительное количество этана и сероводорода. В смолах присутствуют $\boldsymbol{H}$-алканы от $\mathrm{C}_{10}$ до $\mathrm{C}_{24}$, небольшое преимущество имеют нечетные парафины, доминируют $\mathrm{C}_{17}$ и $\mathrm{C}_{19}$, в области $\boldsymbol{H}$-парафинов $\mathrm{C}_{15}-\mathrm{C}_{24}$ видны и разветвленные парафины, наблюдается высокая концентрация изосоединений, особенно пристана и фитана (рисунок). В отличие от смолы полукоксования при автоклавной обработке не образуется олефинов из-за насыщения двойных связей водородом. Ароматические соединения представлены нафталином, $\alpha$ - и $\beta$-метилнафталинами, диметилнафталинами и фенантреном. Кетоны образуются в значительном количестве лишь при конверсии водой, установлены как симметричные (карбонильная группа в середине), так и метилалкилкетоны, из которых доминируют $\mathrm{C}_{17}, \mathrm{C}_{19}$ и $\mathrm{C}_{23}$. По ИКспектрам видно, что смола кон-

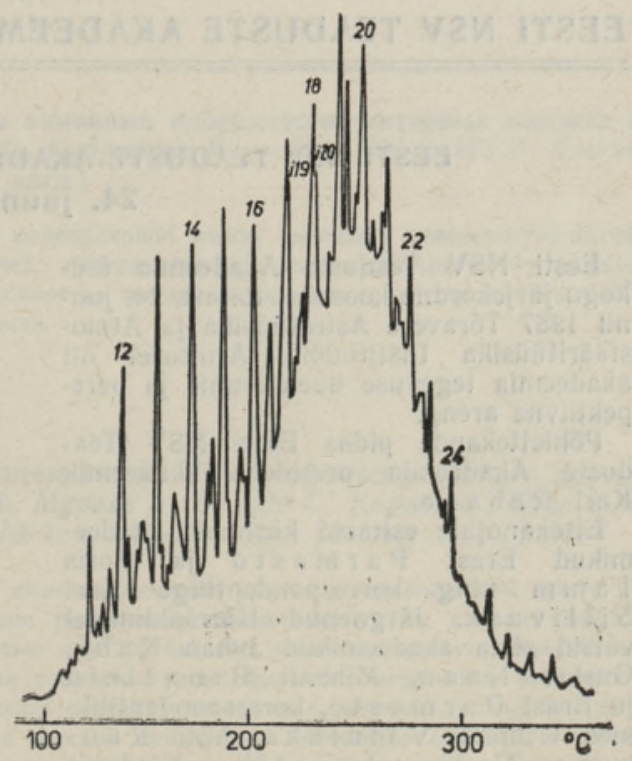

Хроматограмма парафинов смолы каталитической гидрогенизации сланца месторождения Яренга: $12-24-$-парафины, $i 19$ - 20 - изопреноидные углеводороды. 
версии отличается от гидрогениза̄та сильно выраженным поглощением при $3600-3300 \mathrm{~cm}^{-1}$, соответствующим колебаниям -ОН-групп, поглощение при $1700 \mathrm{~cm}^{-1}$, свойственное кетонам, выражено в гидрогенизате намного слабее, чем в смоле конверсии. На всех спектрах видно поглощение при $1600 \mathrm{~cm}^{-1}$, свойственное бензольному кольцу, а также поглощение при 1460 и 1380 см$^{-1}$, свойственное $-\mathrm{CH}_{2}$ и и $-\mathrm{CH}_{3}$-группам.

Поглощение при 840 и $760 \mathrm{~cm}^{-1}$ указывает на ароматические группы. В целом ИК-спектры подтверждают, что гидрогенизат более ароматичный, чем смола конверсии, зато карбонильных групп он содержит меньше.

Сланец Сысольского месторождения Коми АССР содержит 28\% ОВ. Выход из него смолы полукоксования на $8 \%$ ниже выхода из яренгского сланца, а выходы смол автоклавной обработки - почти одинаковы для того и другого.

ОВ сланцев обоих месторождений Коми АССР содержит меньше водорода, чем ОВ сланца Чаганского месторождения, расположенного южнее (Оренбургская область). Поэтому и выход смол из них ниже. Только при введении в процесс дополнительного количества водорода выход смолы повышается до $55 \%$.

\title{
ЛИ ТЕ РАТ У РА
}

1. Сумберг А., Уров К. О составе органического вещества яренгского горючего сланца Коми АССР. - Горючие сланцы, 1987, 4, № 2, 158-165.

2. Наппа Л. А., Клесмент Н. Р., Винк Н. П., Луйк Х. Э. Исследование горючих сланцев Сысольского месторождения Комн АССР. 6. Термическая деструкция в автоклаве. - Горючие сланцы, 1986, 3, № 1, 1-12.

3. Наппа Л., Клесмент И., Винк Н. Гидрогенизация и конверсия горючего сланца Чаганского месторождения. - Изв. АН ЭССР. Хим., 1984, 33, № 2, 87-94.

\author{
Институт химии \\ Академии наук Эстонской ССР
}

Поступнла в редакцию 14/VII 1987

\section{EESTI NSV TEADUSTE AKADEEMIAS}

\section{EESTI NSV TEADUSTE AKADEEMIA OLDKOGU KOOSOLEK 24. juunil 1987}

Eesti NSV Teaduste Akadeemia üldkogu järjekordne koosolek toimus 24. juunil 1987 Tõravere Astrofüüsika ja Atmosfäärifüüsika Instituudis. Arutiusel oli akadeemia tegevuse uuendamine ja perspektiivne areng.

Pōhiettekande pidas Eesti NSV Teaduste Akadeemia president akadeemik Karl Rebane.

Ettekandjale esitasid küsimusi akadeemikud Erast Parmasto ja Boris $\mathrm{T}$ a $\mathrm{mm}$ ning korrespondentliige Karl S i i liv a sk. Järgnenud läbirääkimistel vōtsid. sōna akadeemikud Juhan $\mathrm{Kahk}$, Gustav Na an, Mihhail Bronšte in ja Erast P a rmas to, korrespondentliikmed Gennadi Vain ik ko, Anto R a u k a s, Tšeslav L uštš ik, Vladimir Hižnjakov, Enn Tōugu, Viktor $\mathrm{P}$ a $1 \mathrm{~m}$ ja Peeter S a a r i, Ajaloo Instituudi direktor Raimo $\mathrm{Pu} 1 \mathrm{lat}$, Astrofüüsika ja Atmosfäärifüüsika Instituudi asedirektor Lauri L u u d ning Eesti Biokeskuse direktor Richard Villems. Pi- kema sōnavõtuga esines Eesti NSV Ministrite Nōukogu esimehe esimene asetäitja Indrek Toom e.

Oma lōppsõnas vastas president Karl Reba ne küsimustele ning tänas sõnavõtjaid.

Koosolekust vōttis osa 15 akadeemikut ja 22 korrespondentliiget. Külaliste hulgas olid EKP Keskkomitee büroo liikmekandidaat, Eesti NSV Ministrite Nõukogu esimehe esimene asetäitja Indrek T o o m e, kōrg- ja keskerihariduse minister Väino R a j a n g u, EKP Keskkomitee teaduse ja ôppeasutuste osakonna juhataja asetäitja Vello $\mathrm{Ni}$ inoja ja EKP Tartu Linnakomitee esimene sekretär Tōnu L a a k.

Uksikasjalikum ülevaade koosolekust ja vastuvōetud otsus on avaldatud *Toimetiste» bioloogia- ja füüsika-matemaatikaseeria 1988. aasta 1 . numbris ning ühiskonnateadusteseeria 1988 . aasta 2 . numbris. 